Safa Ahmed Al-Ani

BDS (Master student)

Raya Jasim Al-Naimi

BDS, MSc, PhD (Assist Prof.)

\section{Evaluation of the Effect of Casein Phos- phopeptide-Amorphous Calcium Phos- phate Mousse versus Natural Raw Fresh Milk on Enamel Hardness After a $\mathrm{pH}$ Challenge}

\author{
Ministry Of Health-Nineveh Health Directorate
}

Department of Pedo. Ortho. Preventive Dentistry

College of Dentistry, University of Mosul

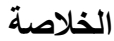

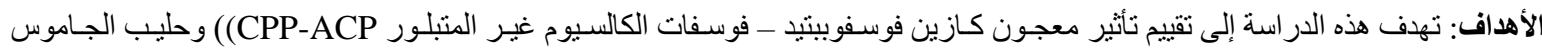

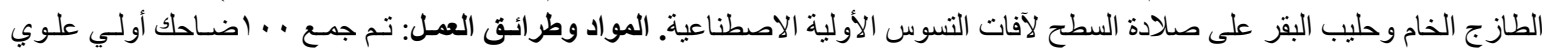

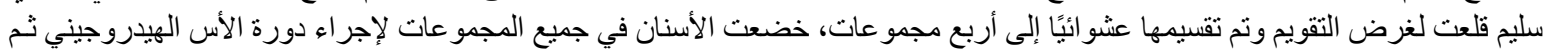

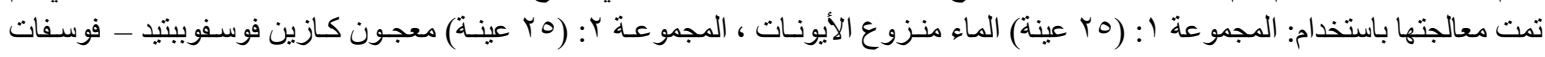

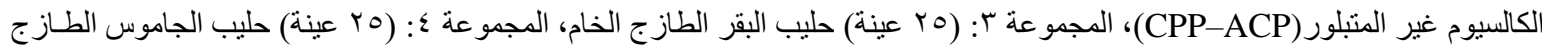

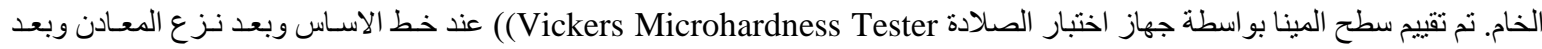

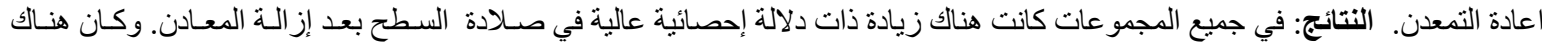

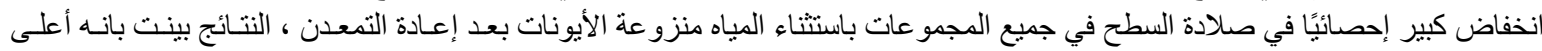

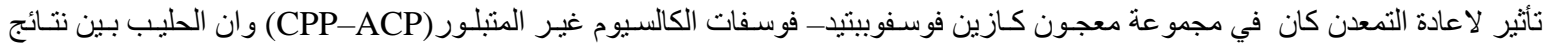

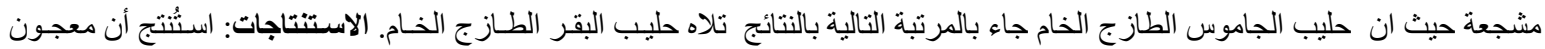

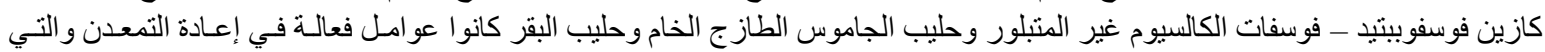

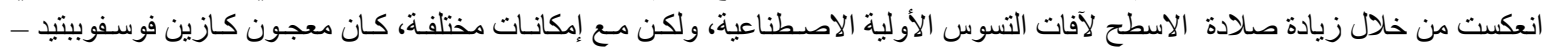

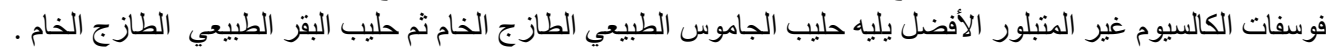

\begin{abstract}
Aims: The aim of this study was to evaluate the effect of CPP-ACP, raw fresh buffalo milk and cow milk on the microhardness of artificial initial caries lesions. Materials and Methods: 100 sound maxillary first premolars were collected and randomly divided into four groups, the teeth in all groups were subjected to $\mathrm{pH}$ cycling procedure then treated with: Group1: $\mathrm{n}$ (25) deionized water, group2: $\mathrm{n}$ (25) CPP-ACP tooth mousse, group3: n (25) fresh raw cow milk, group4: n (25) fresh raw buffalo milk. Enamel surface was assessed by Vickers microhardness test device at a baseline and after demineralization and after remineralization. Results: In all groups, there were high statistically significant reduction of surface microhardness after demineralization. There was high statistically significant increase in surface microhardness in all groups except deionized water after remineralization, the highest remineralization effect was found in $\mathrm{CPP}-\mathrm{ACP}$ tooth mousse group followed by the milk groups that showed encouraging results with fresh raw buffalo milk having superior results then fresh raw cow milk. Conclusions: $\mathrm{CPP}-\mathrm{ACP}$ tooth mousse, raw fresh buffalo milk and cow milk were effective remineralizing agents which were reflected by increasing the surface microhardness of artificial initial caries lesion, but with different abilities, $\mathrm{CPP}-\mathrm{ACP}$ tooth mousse was the best followed by buffalo milk then cow milk.
\end{abstract}

Key words: Casein phosphopeptide-amorphous calcium phosphate, fresh raw milk, microhardness, remineraliziation, demineralization. 
Al-Ani SA. Al-Naimi RJ. Evaluation of the Effect of Casein Phosphopeptide-Amorphous Calcium Phosphate Mousse versus Natural Raw Fresh Milk on Enamel Hardness After a pH Challenge. Al-Rafidain Dent J. $2021 ; 21(1): 14-24$.

DOI: 10.33899/rden.2020.127142.1032 C2021, College of Dentistry, University of Mosul Received: 18/5/2020 Sent to Referees: 20/5/2020 Accepted for Publication: 14/6/2020 This is an open access article under theCCBY4.0license (http://creativecommons.org/licenses/by/4.0/)

\section{INTRODUCION}

Dental caries is considered as a major public oral health problem worldwide ${ }^{(1)}$. To control this problem, management must start with the first sign of the disease which appears as white spot lesion also known as initial carious lesion and is defined as a non-cavitated carious lesion restricted to visual change in color of enamel and texture ${ }^{(2)}$.

The principles of minimum invasive technique in dentistry dictate the need for clinical effective measures to remineralize early caries lesions. While fluoride-based remineralization, agents are the cornerstone of caries management techniques, a number of new remineralization procedures commercially available that concentrate or enhance deeper remineralization of caries lesions and decrease the potential risks related with high-fluoride products, and control caries disease over a lifetime ${ }^{(3)}$.

Casein phosphopeptide - amorphous calcium phosphate is considered a bioactive agent, milk base products. Casein phosphopeptide (CPP) is capable of stabilizing amorphous calcium phosphate (ACP) and also localizes it in dental plaque. This nanocomplex represents as a reservoir for bioavailable calcium and phos- phate, so facilitates remineralization by maintaining the solution in supersaturated level ${ }^{(4,5)}$.

Milk has a high ability in supporting enamel remineralization. Milk can be obtained from different sources. Casein of the milk which is the main protein of milk, high concentration of phosphate and calcium. All these play an important role in preventing demineralization and promoting remineralization ${ }^{(6,7)}$.

The aim of the current study is to evaluate the effect of casein phosphopeptide- amorphous calcium phosphate versus natural raw fresh buffalo and cow milk on enamel hardness after a $\mathrm{pH}$ challenge.

\section{MATERIALS AND METHODS}

The study was approved by Research Ethics Committee board (University of Mosul, College of Dentistry, REC reference No. POP/S.14/6/20).

\section{Sample Collection}

The sample of this study consisted of (100) human permanent first premolars extracted for the purpose of orthodontic treatment. After extraction, the teeth were cleaned with tap water and examined with $10 \mathrm{X}$ magnifying lens. The selection of the teeth followed specif- 
ic criteria: the teeth must be sound, free from enamel defects, decay, stain, cracks, demineralization, fluorosis and restorations. The teeth were stored in $0.1 \%$ thymol solution.

\section{Sample Preparation}

The teeth were cleaned with rubber cup and non-fluoridated pumice by using low speed hand piece, then the crowns of the teeth were separated from the roots at cemento-enamel junction by using diamond disc in hand piece under copious of water, then the teeth were adapted in a cold cure acrylic mold with specific dimensions (20mm diameter, $15 \mathrm{~mm}$ depth) in a technique that the buccal surfaces of crowns were exposed and paralleled to the floor as seen in Figure (1). The buccal surface of each tooth was grounded and polished using grit paper (grit 400, 600) ten times in one direction, in order to get a flat surface of each specimen of tooth for microhardness testing ${ }^{(8)}$.

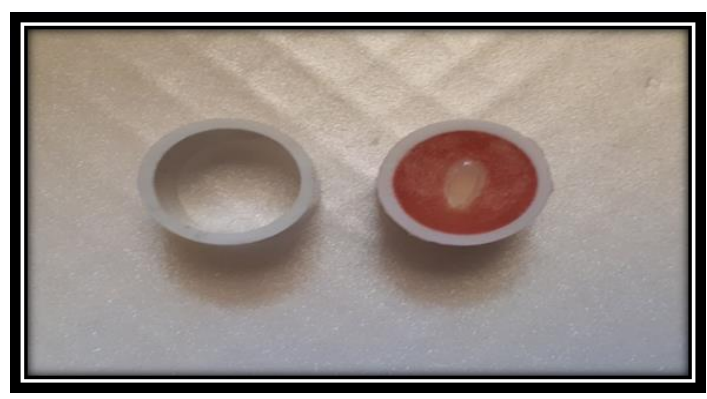

Figure (1): Teeth in a cold cure acrylic mold

\section{Materials:}

Commercially available casein phosphopeptide - amorphous calcium phosphate topical cream with bioavailable calcium and phosphate (GC America, Recldent, Alsip, USA) was used in remineralization of one group of the sample, in addition to raw fresh buffalo and cow milk that were obtained from a local farm dealer (local breed) in Mosul City by single milking dose, the milk was kept cold in the refrigerator.

\section{Groups Design and Methods:}

Group 1: (control negative) $n=25$ the teeth were subjected to $\mathrm{pH}$ cycling procedure for ten days and then were stored in deionized water until subjected to microhardness test.

Group 2: $\mathrm{n}=25$ the teeth were subjected to $\mathrm{pH}$ cycling procedure for ten days and then $\mathrm{CPP}-\mathrm{ACP}$ tooth mousse was applied. The protocol of application GC tooth mousse in this study was followed the manufacturer's instructions by application thin layer of the cream on each tooth specimen by fine brush for 3 minutes, then again the cream was distributed by the brush and left for 30 minutes, this procedure repeated two times daily for 7 days ${ }^{(9)}$. Between sessions the teeth were stored in deionized water. 
Group 3: $n=25$ the teeth were subjected to $\mathrm{pH}$ cycling procedure for ten days and then, the teeth were immersed in $250 \mathrm{ml}$ of raw fresh cow milk for 50 hours continuously. The milk was replaced every 2 hours ${ }^{(10)}$. Then the teeth were stored in deionized water until subjected to microhardness test.
Group 4: $\mathrm{n}=25$ the teeth were subjected to $\mathrm{pH}$ cycling procedure for ten days and then, the teeth were immersed in $250 \mathrm{ml}$ of raw fresh buffalo milk for 50 hours continuously, the milk was replaced every 2 hours ${ }^{(10)}$. Then the teeth were stored in deionized water until subjected to microhardness test. All the groups can be seen in Figure (2).

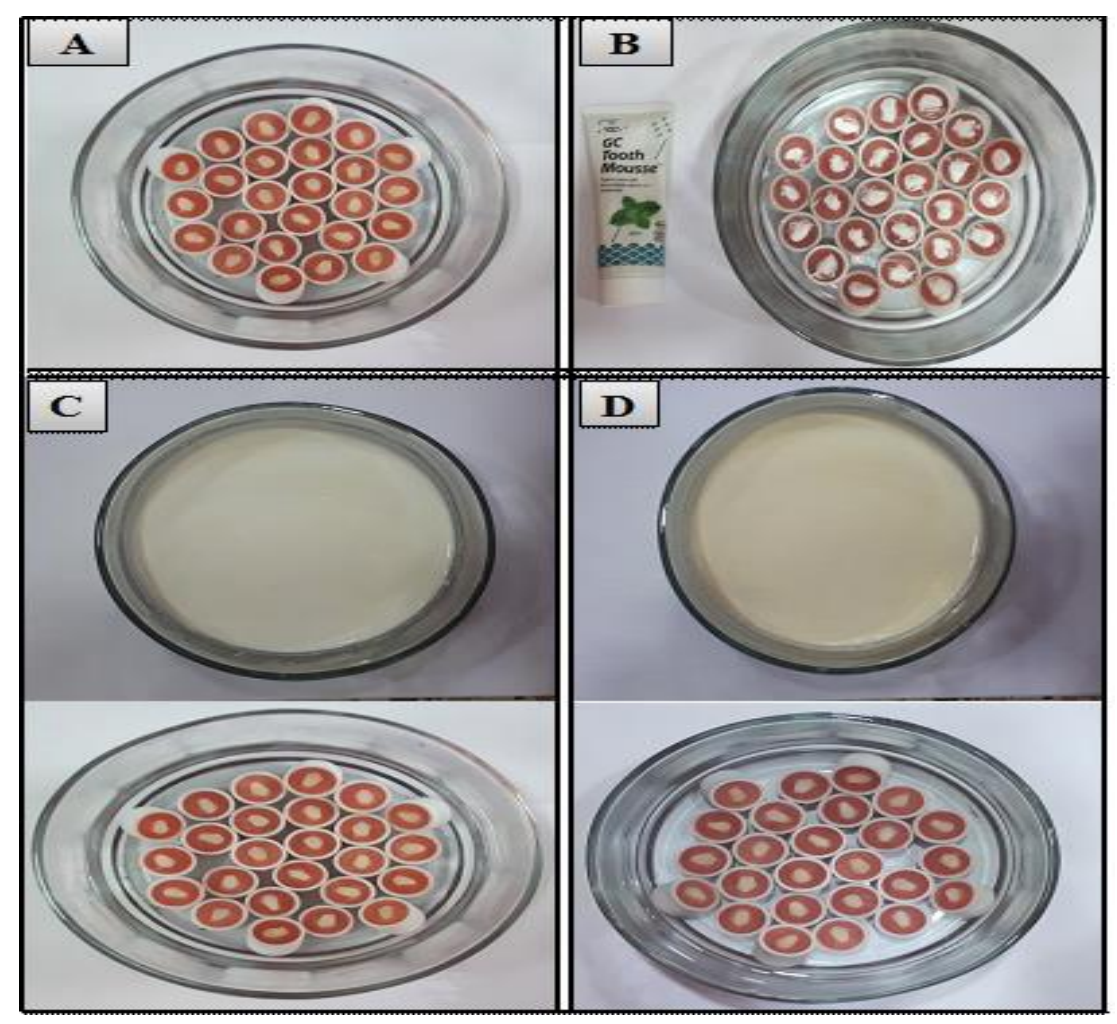

Figure (2): Groups design, (A)Teeth immersed in deionized water after pH cycling, (B) CPP-ACP tooth mousse applied after $\mathrm{pH}$ cycling, (C) Teeth immersed in cow milk after $\mathrm{pH}$ cycling, (D) Teeth immersed in buffalo milk after $\mathrm{pH}$ cycling.

Formation of Initial Like Caries Lesion in Enamel Surface of Specimens

The formation of initial like caries lesion followed the protocol of demineralizing and remineralizing solutions preparation, and adjustment of the $\mathrm{pH}^{(11,12)}$. The demineralizing solution composed of calcium chloride 1 $\mathrm{mM} / \mathrm{L}$, acetic acid $0.075 \mathrm{M} / \mathrm{L}$, potassium phosphate $2 \mathrm{mM} / \mathrm{L}$ and deionized water $1 \mathrm{~L}$, 
while the remineralizing solution was composed of potassium phosphate $0.9 \mathrm{mM} / \mathrm{L}$, potassium chloride $150 \mathrm{mM} / \mathrm{L}$, calcium nitrate $1.5 \mathrm{mM} / \mathrm{L}$ and deionized water $1 \mathrm{~L}$, and the $\mathrm{pH}$ values of demineralization solution were adjusted at 4.3 and the remineralization solutions at 7 and were measured every day by using $\mathrm{pH}$ meter and adjusted if necessary.

\section{The pH Cycling Procedure :}

Each group was immersed in $250 \mathrm{ml}$ of the demineralization solution and retained for 6 hours. Then the teeth were removed and rinsed with running deionized water for one minute. After that, each group was immersed in $250 \mathrm{ml}$ of remineralizing solution for 17 hours .This procedure was done one time each day and repeated for a period of 10 days ${ }^{(11,12)}$.

\section{Microhardness Test:}

The enamel hardness of the specimens was measured by Vickers microhardness tester device (Wolpert, Germany). The measurements were conducted using 500 gm load for $15 \mathrm{sec}-$ onds to the occlusal third of the enamel surface of the specimens. The time and load were constant for all the specimens for the whole study. For each specimen three indentations were measured and the average value of them was calculated.

The Vickers hardness number (VHN) was calculated after measuring the two diagonal $\mathrm{d} 1, \mathrm{~d} 2$ length of the square impression which was formed by the indenter using scaled microscope (70X lens) in the device ${ }^{(13,14)}$ and then converted to VHN by using the equation below:

$\mathrm{HV}=1.8544\left(\mathrm{~F} / \mathrm{d}^{2}\right)$, where $\mathrm{HV}$ is a Vicker hardness in $\mathrm{Kgf} / \mathrm{mm}^{2}$ (Mpa)

$\mathrm{F}$ : the indentation load in kilogram-force (Kgf). $\mathrm{d}:$ the diagonal of the indentation in millimeter $(\mathrm{mm}) . \mathrm{d}=\mathrm{d} 1+\mathrm{d} 2 / 2$

\section{RESULTS}

Table (1) depicts one way analysis of variance (ANOVA) in the comparison of mean values of VHN between the groups in each baseline, demineralization and remineralization variables. The results showed that there was no statistical significant difference in mean hardness numbers of the teeth enamel at the base line between and within groups before starting the experiment, also there was no statistical significant difference in mean hardness numbers at demineralization, while there was a highly statistically significant difference in remineralization protocols between the different group types $\mathrm{p} \leq 0.01$. 
Table (1): ANOVA test for VHN mean values of the variables between the groups

\begin{tabular}{ccccccc}
\hline Microhardness & & $\begin{array}{c}\text { Sum of } \\
\text { Squares }\end{array}$ & df & $\begin{array}{c}\text { Mean } \\
\text { Square }\end{array}$ & F & Sig. \\
\hline Baseline & Between Groups & 80.990 & 3 & 26.997 & 0.344 & 0.793 \\
& Within Groups & 7530.400 & 96 & 78.442 & & \\
Temineralization & Total & 7611.390 & 99 & & & \\
& Between Groups & 9.120 & 3 & 3.040 & 0.181 & 0.909 \\
& Within Groups & 1616.640 & 96 & 16.840 & & \\
Remineralization & Total & 1625.760 & 99 & & & \\
\cline { 2 - 6 } & Between Groups & 58140.990 & 3 & 19380.330 & 2412 & $0.000 *$ \\
& Within Groups & 771.200 & 96 & 8.033 & & \\
& Total & 58912.190 & 99 & & & \\
\hline
\end{tabular}

Df: degree of freedom *Highly statistically significant difference at $\mathrm{p} \leq 0.01$.

Table (2) demonstrates means and standard deviation, Duncan's multiple range test of VHN mean values of the teeth between the groups. The results of the baseline readings showed that the hardness values were ranging between $(289.88$ - 292.16) for the different groups and there was no statistical difference between the groups. Also no statistical significant difference between the means in demineralization between the groups was observed.
In remineralization, there was a statistically significant difference between the groups, the highest VHN mean value was found in CPP-ACP group followed by buffalo milk, then cow milk groups, while the lowest value was found in deionized water group that was not treated with a remineralizing agent. However, none of the remineralizing treatment options increased the VHN mean value to the baseline mean.

Table (2): Means values, Standard deviation and Duncan's Multiple Range test of VHN mean values of the variables between the groups

\begin{tabular}{|c|c|c|c|c|}
\hline \multirow[b]{2}{*}{ Groups } & \multirow[t]{2}{*}{ Variables } & \multirow[b]{2}{*}{ Baseline } & \multirow[b]{2}{*}{ Demineralization } & \multirow[b]{2}{*}{ Remineralization } \\
\hline & & & & \\
\hline Deionized & Mean & $289.88 \mathrm{a}$ & $56.800 \mathrm{a}$ & $57.240 \mathrm{~d}$ \\
\hline \multirow[t]{2}{*}{ Water } & $\mathbf{N}$ & 25 & 25 & 25 \\
\hline & Std. Deviation & 8.86623 & 3.09570 & 2.75802 \\
\hline \multirow[t]{2}{*}{ CPP-ACP } & Mean & $292.16 \mathrm{a}$ & $56.400 \mathrm{a}$ & $124.680 \mathrm{a}$ \\
\hline & $\mathbf{N}$ & 25 & 25 & 25 \\
\hline
\end{tabular}




\begin{tabular}{lcccc}
\hline & Std.Deviation & 9.02164 & 4.69042 & 2.83901 \\
Cow Milk & Mean & $290.68 \mathrm{a}$ & $56.400 \mathrm{a}$ & $83.280 \mathrm{c}$ \\
& $\mathbf{N}$ & 25 & 25 & 25 \\
& Std.Deviation & 7.32416 & 2.48328 & 3.06213 \\
Buffalo & & & & \\
Milk & Mean & $290.04 \mathrm{a}$ & $57.120 \mathrm{a}$ & $92.440 \mathrm{~b}$ \\
& $\mathbf{N}$ & 25 & 25 & 25 \\
Total & Std.Deviation & 10.00616 & 5.44151 & 2.66271 \\
& & & & \\
& Mean & 290.69 & 56.680 & 100.410 \\
& $\mathbf{N}$ & 100 & 100 & 24.39411 \\
\hline
\end{tabular}

$\mathrm{N}:$ Number of the specimens, Std. Deviation: Standard Deviation. Different Small letters indicate statistically significant difference within the same column (vertically) $\mathrm{p} \leq 0.05$.

\section{DISCUSSION}

Microhardness studies provide a relatively simple, easy nondestructive, and rapid method in mineralization studies. Therefore, in the present study, the microhardness values for each specimen are measured three times at the baseline, and after $\mathrm{pH}$ cycling procedures that caused the induction of carious lesion (demineralization), and after the remineralization process. It also allows repeated measurements taken over a period of time of the same specimen, and needs tiny area of specimen surface for

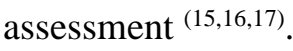

In the past fluoride was the corner stone of most remineralization studies ${ }^{(18,19)}$ but due to the increased risk of dental fluorosis especially in children which has led to recommendation of the need to assess the amount of exposure of the population before introducing any additional fluoridation for caries prevention ${ }^{(20)}$ due to fear of increasing dental fluorosis. Therefore, there is a need for development of other novel enamel remineralization systems other than fluoride. The most promising of these remineralizing agents is the $\mathrm{CPP}-\mathrm{ACP}{ }^{(3)}$.

Our study showed that the results of $\mathrm{CPP}-\mathrm{ACP}$, fresh raw buffalo and cow milk application resulted in remineralization, the results were highly promising considering the two types of milk used and is considered the first study that has used fresh raw buffalo and cow milk, and there was an increase in hardness values of the initial caries lesion that was created.

In Table (1), the results showed there were no significant difference at baseline and demineralization between and within groups due to the use the same protocol of demineralization for all groups, while in demineralization there was a high significant difference between and 


\section{Al-Ani SA. Al-Naimi RJ}

within groups due to the differences in remineralizing ability of each treatment regime.

In Table (2), the results exhibited no significant difference between groups at baseline. Also, at the demineralization there was no significant difference between the groups due to the use of same $\mathrm{pH}$ cycling procedure in all groups, while in remineralization, there was a significant difference between the groups.Casein phosphopeptides amorphous calcium phosphate is a bioactive agent based on milk products that replicates the properties of the milk caseins, so it has the ability to bind calcium and phosphate ions in order to stabilize calcium phosphate in the solution and increase their level in dental plaque. Beside that CPP-ACP adheres to soft tissues, hydroxyapatite and supplies free calcium and phosphate ions, so maintaining a state of supersaturated level of calcium and phosphate in proximity to the enamel surface lesion, thereby reducing demineralization and enhances remineralization by reforming crystals of calcium phosphate $(21,22)$.

The result of CPP-ACP group is in agreement with Ma et al. ${ }^{(23)}$ that concluded that according to the results which were analyzed data in clinical and in vitro, $\mathrm{CPP}-\mathrm{ACP}$ exhibited excellent remineralization effect of weight spot lesions with high percentages of weight spot lesions regression and high surface microhardness recovery.Contrary, this result is in disagreement with Vyavhare et al. ${ }^{(24)}$ that found CPP-ACP did not remineralize enamel surface and it could only be used as adjunct to fluoride, but could not be recommended to be applied as an alternative to it. The current study demonstrated that milk showed a remineralizing effect, which might be attributed to the high concentration values of calcium and phosphate ${ }^{(25)}$. Also, milk has bioactive peptides, casein phosphor proteins that are strongly absorbed in the surface of enamel and able to reduce the activity and adsorption of glucosyltransferase enzymes, also preventing or reducing the dissolution of the enamel ${ }^{(26)}$. The results of remineralization effect of milk are in agreement with Vieira et al. ${ }^{(27)}$ that concluded that whole milk showed significant higher gain of enamel microhardness of eroded enamel as compared to filtered water. 
Our study revealed that $\mathrm{CPP}-\mathrm{ACP}$ exhibited the highest remineralization, this could be due to the concentrated amount of calcium and phosphate and casein in the synthetic product of CPP-ACP tooth mousse in comparison to milk. Although the increase in the microhardness was significant in both types of milk used, but it was more and showed superior results in buffalo milk than cow milk which might be attributed to that the calcium content in buffalo milk which is more than the cow milk and the protein ( $80 \%$ of it casein) was higher in buffalo milk than cow milk also it might be attributed to the reason that the whey protein is greater in buffalo compared to cow milk ${ }^{(28)}$. This result was in agreement with Vongsavan et al. ${ }^{(29)}$ who concluded that the mean microhardness value increased in both buffalo and cow milk in dry milk powder formula, but was more in buffalo milk than cow milk.

\section{CONCLUSION}

Within the limitations of the current study, the demineralization process by $\mathrm{pH}$ cycling procedure decreased the microhardness and created initial like caries lesion on enamel surface. CPP-ACP tooth mousse, raw fresh buffalo milk and cow milk showed promising remineralizing effect which were reflected by increasing surface microhardness of artificial initial caries lesion, but with different abilities, $\mathrm{CPP}-\mathrm{ACP}$ tooth mousse had the superior effect followed by fresh raw buffalo milk which was superior to fresh raw cow milk in remineraliza- tion abilities expressed by increased hardness scores.

\section{REFERENCES}

1. Elidriss SM, Naidoo S. Prevalence of dental caries and toothbrushing habits among preschool children in Khartoum State, Sudan. Int Dent J. 2016; 66(4): 215-220.

2. Bondioni E. Carious lesions and first restorative treatment: Adopted by the General Assembly: September 2019, San Francisco, United States of America. Int Dent J. 2020;70(1): 5-6.

3. Philip N. State of the art enamel remineralization systems: The next frontier in caries management. Caries Res. 2019; 53(3): 284-295.

4. Hegde MN, Moany A. Remineralization of enamel sub-surface lesions with casein phosphopeptide-amorphous calcium phosphate: a quantitative energy dispersive $\mathrm{X}$ ray analysis using scanning electron microscopy: an in vitro study. $J$ Conserv Dent. 2012;15(1): 61-67.

5. Talaat DA, Abdelrahman AA, Abdelaziz RH, Nagy D. Effect of two remineralizing agents on initial caries-like lesions in young permanent teeth: An in vitro study. $J$ Contemp Dent Pract. 2018;19(10): 11811188.

6. Rahardjo A, Sahertian R, Ramadhani S, Maharani D, Latief F. The effect of milk or its combination with tea and $0.2 \% \mathrm{NaF}$ on dental enamel demineralization analyzed 


\section{Al-Ani SA. Al-Naimi RJ}

by micro computed tomography. J. Dent. Indones. 2014; 21(20): 53-56.

7. Yendriwati Y, Sinaga R, Dennis D. The increase of tooth enamel hardness score after cow milk immersion compared to artificial saliva on demineralized tooth. World $J$ of Dent. 2018; 9(6): 439-443.

8. Al-Sayyab M. (2000). The potential effect of combined $\mathrm{CO} 2$ laser and fluoride on acid resistance of human dental enamel and root surface in vitro. $\mathrm{PhD}$ thesis, Preventive Dentistry, University of Baghdad.

9. Chaudhary I, M Tripathi A, Yadav G, Saha S. Effect of casein phosphopeptideamorphous calcium phosphate and calcium sodium phosphosilicate on artificial carious lesions: An in vitro study. Int J Clin Pediatr Dent. 2017; 10(3): 261-266.

10. Abd-elmonsif NM, El-Zainy MA, Abdelhamid MM. Comparative study of the possible effect of bovine and some plantbased milk on cola-induced enamel erosion on extracted human mandibular first premolar (scanning electron microscope and $\mathrm{X}$-ray microanalysis evaluation). Future Dent J. 2017; 3(1): 22-27.

11. Featherstone J, Oreilly M, Shariati M, Bruder S. Enhancement of remineralization in vitro and in vivo. In: Leach S.A. Ed. Factor relating to demineralization and remineralization of the teeth. Oxford IRL Press, 1986.

12. Fahad AH, Al-Weheb AM. Effect of casein phosphopeptide-amorphous calcium phosphate on the microhardness and microscopic features of the sound enamel and initial caries-like lesion of permanent teeth, compared to fluoridated agents. J Bagh College Dentistry. 2012; 24(4): 114-115.

13. Yao L, Fang CH. A hardness measuring method based on hough fuzzy vertex detection algorithm. IEEE Trans. Industrial Electronics. 2006; 53(3): 950-962.

14. Dominguez-Nicolas SM, Wiederhold P. Indentation image analysis for Vickers hardness testing. Conference on Electrical Engineering, Computing Science and Automatic Control (CCE). 2018; 5(7): 1-6.

15. Neto FCR, Maeda FA, Turssi, CP, Serra MC. Potential agents to control enamel caries-like lesions. J Dent. 2009; 37(10): 786-790.

16. Aydin B, Pamir T, Baltaci A, Orman MN, Turk T. Effect of storage solutions on microhardness of crown enamel and dentin. Eur J Dent. 2015; 9(2): 262-266.

17. Kamal D, Hassanein H, Elkassas D, Hamza H. Complementary remineralizing effect of self-assembling peptide (P11-4) with CPPACPF or fluoride: An in vitro study. J Clin Exp Dent. 2020; 12(2): e161-e168.

18. Marinho VC, Worthington HV, Walsh T, Chong LY. Fluoride gels for preventing dental caries in children and adolescents. Cochrane database Syst Rev. 2015; (6): CD002280.

19. Shahid M. Regular supervised fluoride mouthrinse use by children and adolescents 


\section{Casein Phosphopeptide-Amorphous Calcium Phosphate}

associated with caries reduction. Evid Based Dent. 2017; 18(1): 11-12.

20. Hattab F N. An Update on Fluorides and Fluorosis with Reference to Oral Health Status in the Gulf Region: Review. AJDS. 2020; 3(1): 27-48.

21. Chandak, S, Bhondey A, Bhardwaj A, Pimpale J, Chandwani M. Comparative evaluation of the efficacy of fluoride varnish and casein phosphopeptide - amorphous calcium phosphate in reducing streptococcus mutans counts in dental plaque of children: An in vivo study. $J$ Int Soc Prev Community Dent; 2016; 6(5): $423-429$.

22. Indrapriyadharshini K, Kumar MPD, Sharma K, Iyer K. Remineralizing potential of CPP-ACP in white spot lesions: A systematic review. Indian J Dent Res. 2018; 29(4): 487-496.

23. Ma X, Lin X, Zhong T, Xie F. Evaluation of the efficacy of casein phosphopeptide-amorphous calcium phosphate on remineralization of white spot lesions in vitro and clinical research: A systematic review and meta-analysis. BMC Oral Health. 2019; 19(1): 295.
24. Vyavhare S, Sharma DS, Kulkarni VK. Effect of three different pastes on remineralization of initial enamel lesion: An in vitro study. J ClinPediatr Dent. 2015; 39(2): 149-160.

25. Kashket S, De Paola DP. Cheese consumption and development and progression of dental caries. Nutr Rev. 2003; 60(19): 327-334.

26. Moi GP, Silva CB, Garcia-Leite E.S, Bertaia CA, Santos RB, Costa-Nobre PX, Silva AM. Cariogenic Potential of Human Milk, Bovine Milk and Milk Substitutes in Early Childhood. Acad J Ped Neonatol. 2017; 5(1): 555-711.

27. Vieira AR, Chung C, Raffensperger SK, Muluk PD. Milk reverts the effects of an enamel erosive but healthy Diet. Pesq Bras Odontoped Clin Integr. 2018; 18(1): 1-8.

28. Khedkar CD, Kalyankar SD, Deosarkar SS. Buffalo Milk. In: Caballero, B., Finglas, P., and Toldrá, F. (eds.) The Encyclopedia of Food and Health vol.1, Oxford: Academic Press. U.S.A. 2016.pp. 522-528.

29. Vongsavan K, Rirattanapong P, Surarit R. Association between milk temperature and microhardness of enamel caries. Southeast Asian J Trop Med Public Health. 2017; 48(5): 1140-1144. 